one cannot help wondering why she has not discussed in the text (although giving some of the references in the bibliography) the recent exhaustive work by Laws on the population dy namics of the elephants in the national parks of Kenya and Uganda.

Perhaps the least satisfactory chapter is the last, on conservation. One might have hoped that Dr Sikes would have had some constructive suggestions for the solution of the enormous problem of elephant over-population which faces some East African parks today. It is all very well to suggest as she does that an annual, sustained-yield crop should be taken from the elephant stocks, but what of the present over-populations? No suggestions on how to deal with these are given. It is no use bemoaning the fact that no scientists were appointed to monitor the growth of the large mammal numbers at the time the parks were created and then sniping at the 'foreign scientists' financed by 'foreign investors' (sic) who are now working in the parks and trying desperately to make up for the time which has been lost. To suggest, as Dr Sikes does, that there is something sinister in this and that these scientists 'know little of the (country's) heritage and care less' is plainly ridiculous. In fact, research units in the parks of Kenya, Uganda and Tanzania receive funds from a variety of sources including the national universities and the national governments. Similarly the European, American and African staff of the research units are dedicated people, well aware of the shortcomings of previous policies in the formation of which they played no part. These people, too, are conscious of the urgency of the problems and if they 'suddenly' produce management proposals it is because only now are the results of their research becoming available.

However, apart from this rather querulous last chapter, the book contains a useful compilation and discussion of the available references to the African elephant in the scientific literature, and, in spite of its high cost, it will be constantly consulted by students of the species.

MICHAEL WOODFORD

\title{
East African Mammals, by Jonathon Kingdon. Academic Press, $£ 12.00$
}

East Africa is popularly the part of the world most associated with wildlife, especially mammals. Nevertheless, it has been surprisingly difficult to get a balanced picture of the mammal zoology. No modern book deals in depth with them all. Jonathon Kingdon has produced the first of three volumes which will do just this, telling us about the morphology, ecology and behaviour of all the mammal species he recognises as living in the area. Further, he has done this in an unusual way. There are no photographs; instead he has used his own drawings, some in colour, to illustrate not only the outward appearance and postures of the animals but also their muscular and skeletal structures.

Volume I opens with a short account of his method, followed by three chapters on the environment, topography, climate, vegetation, geology and evolutionary trends, with two 'appendices', one on the Bwamba Forest and the other on mammal anatomy. The next 300 pages cover the general zoology of the primates, hyraxes, pangolins, aardvark and dugong - this part would have been more helpful divided into chapters - and the volume ends with a list of families, a gazeteer, and a most comprehensive and useful bibliography.

While the text, taking the reader easily through the species and highlighting with well chosen local anecdote, is good, to many people the import of the book will be in its illustrations. The standard of his 
hundreds of drawings, ranging from the simple thumbnail sketch showing a pose to detailed anatomical drawings, is generally excellent, though occasionally, as with the page of de Brazza's monkeys, there has been a tendency to caricature. One or two, for example those of the dugong swimming, are not helpful and detract from the high standard elsewhere.

Once or twice the author steps into fields he does not fully understand. I would question his wisdom in ascribing misshapen lions' skulls from early 20th century zoos to lack of muscular exercise; there are other factors which might at that time have been playing their part. Also, why on page vi, in a map of the whole of Africa, emphasise the desert of SW Africa 2000 miles from his subject area and ignore the Sahara only 500 miles away? These however are small points when compared to the wealth of knowledge and experience he has put into this book. I wish that I had been able to read it before my first visit to East Africa.

M.R. BRAMBELL

An Atlas of Speciation in African Passerine Birds, by B.P. Hall and R.E.

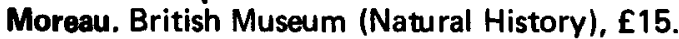

Birds of Surinam, by Franf̧ois Haverschmidt. Oliver \& Boyd, $f 13$.

A Checklist of the Birds of Ethiopia, by Emil K. Urban and Leslie $H$.

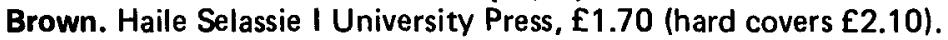

Bibliography of the Avifauna of Ethiopia, by Emil K. Urban. Haile Selassie I University Press, 42p.

It is sad to see Reg Moreau's name appear for the last time on a newly published book, but it is one which is worthy of his great knowledge of Africa's avifauna. Together with Pat Hall, who because of his last illness had to do most (if not all) of the labour of actually plotting the locations of specimens on maps, he completed a titanic task. The mapping of all precise locations of reliable specimen records, together with some reliable sight records, for all the 900 species of songbirds resident in Africa south of the Sahara, provides, as Ernst Mayr says in his introduction, 'a veritable gold mine of information'. It is the raw material for innumerable studies in biogeography, ecology and evolution, which the fortunate students of African birds will in future be able to quarry and cannibalise. Very much of a work for the specialist, it will be quite invaluable for the specialist who turns to it.

Haverschmidt's excellent Birds of Surinam, with fine colour and black-and-white illustrations by Paul Barruel, first appeared in 1968, and it is good news that the demand for it has been so great as to stimulate the present reprint. The Chief Justice of the territory that is still better known to many as Dutch Guiana is well known as one of the ablest and most meticulous of modern ornithologists, and his feat takes us back to the time when ability to write an avifauna of the region was almost a sine qua non for governors of British East African colonies. In effect, we have here an avifauna for the northern half of South America, though, alas, a mite too heavy to take into the field, even in a knapsack.

The two booklets from the Haile Selassie I University Press will both prove invaluable to bird-watchers visiting Ethiopia. The first is a complete check-list of all the birds of a country which has many endemics to offer, and the second a most useful bibliography. The two authors are undoubtedly the two ornithologists with the greatest knowledge of Ethiopian birds today.

RICHARD FITTER 